\title{
Am-Np (Americium-Neptunium)
}

\section{H. Okamoto}

The Am-Np phase diagram was calculated by [1993Oga] using a regular solution model (see [19990ka]). The phase diagram was incomplete, as low-temperature allotropes of both terminal elements were not taken into account.

Figure 1 shows a complete Am-Np phase diagram calculated by [2010Kur] based on the thermodynamic database created consistently for actinide elements.

Table 1 shows Am-Np crystal structure data. The approximate composition range for each phase was read from the phase diagram.

\section{References}

1993Oga: T. Ogawa, Alloying Behaviour among U, Np, Pu, and Am Predicted with the Brewer Bond Model, J. Alloys Compd., 1993, 194(1), p 1-7

19990ka: H. Okamoto, Am-Np (Americium-Neptunium), J. Phase Equilib., 1999, 20(4), p 450

2010Kur: K. Kurata, Thermodynamic Database on U-Pu-Zr-NpAm-Fe Alloy System II-Evaluation of $\mathrm{Np}$, Am, and $\mathrm{Fe}$ Containing Systems, IOP Conference Series: Materials Science and Engineering, Vol 9, 2010, 12023, 8 pp

Table 1 Am-Np crystal structure data

\begin{tabular}{lccccc}
\hline Phase & Composition, at.\% Np & Pearson symbol & Space group & Strukturbericht designation & Prototype \\
\hline$(\gamma \mathrm{Am})$ & $0-6$ & $c / 2$ & $I m \overline{3} m$ & $A 2$ & $\mathrm{~W}$ \\
$(\beta \mathrm{Am})$ & $0-2$ & $c F 4$ & $F m \overline{3} m$ & $\mathrm{~A} 1$ & $\mathrm{Cu}$ \\
$(\alpha \mathrm{Am})$ & $0-1$ & $h P 4$ & $P 6_{3} / m m c$ & $A 3^{\prime}$ & $\mathrm{L}$ \\
$(\gamma \mathrm{Np})$ & $99-100$ & $c I 2$ & $I m \overline{3} m$ & $A_{d}$ & $\mathrm{~W}$ \\
$(\beta \mathrm{Np})$ & 100 & $t P 4$ & $P 24_{1} 2$ & $A_{c}$ & $\alpha \mathrm{Np}$ \\
$(\alpha \mathrm{Np})$ & 100 & $o P 8$ & $P n m a$ & & $\alpha \mathrm{Np}$ \\
\hline
\end{tabular}

Weight Percent Neptunium

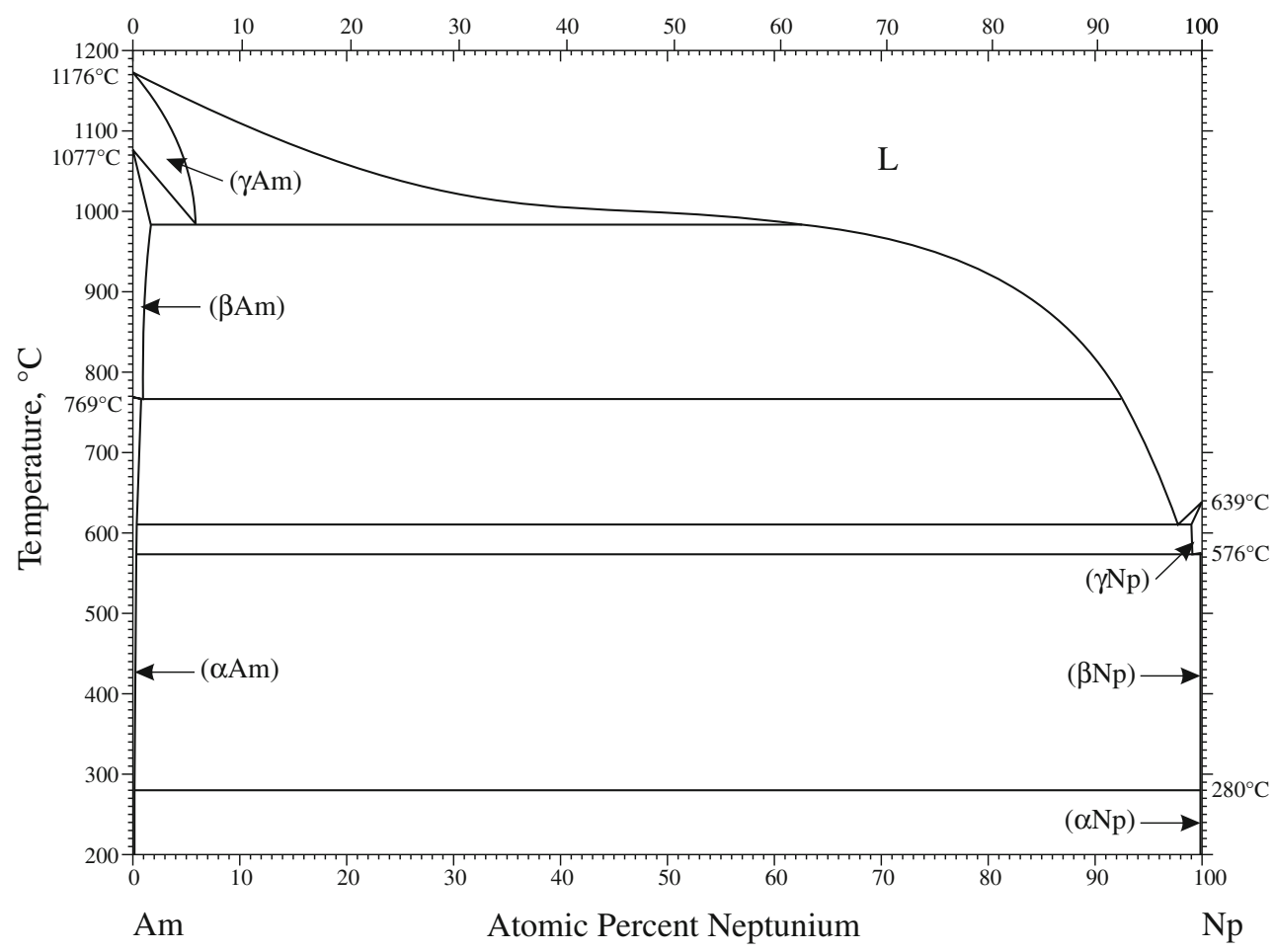

Fig. 1 Am-Np phase diagram 